\title{
Teaching epidemiology: Nursing student achievement in a multi-campus, multi-faculty, distance delivery course
}

\author{
Maria Gilson deValpine, Thomas P. Boudrot, Matthew Jones \\ Department of Nursing, James Madison University, Portland, United States \\ Correspondence: Maria Gilson deValpine. Address: Department of Nursing, James Madison University, Portland, United \\ States. E-mail: devalpmg@jmu.edu \\ Received: June 25, $2013 \quad$ Accepted: August 8, $2013 \quad$ Online Published: September 28, 2013 \\ DOI : 10.5430/jnep.v4n2p67 URL: http://dx.doi.org/10.5430/jnep.v4n2p67
}

\begin{abstract}
Background: A common epidemiology curriculum was developed by a nurse epidemiologist and delivered by generic nursing faculty on 5 campuses of a western U.S. university school of nursing. The objective was to assess whether student achievement would be affected in this multi-campus, multi-faculty, distance delivery common epidemiology course.

Methods: 329 nursing students admitted to 5 campuses of one university were enrolled by cohort in an epidemiology course between 2009 and 2011. 138 students were enrolled by cohort in four courses taught by the nurse epidemiologist who developed the course. The remaining 191 students were divided into sections, enrolled in the common course, and taught by multiple nursing faculty members, variously prepared in the field of public health. Final test score averages were compared between 6 cohorts of students: 1 large set of cohorts taught by the nurse epidemiologist who developed the common course but prior to its implementation, and 5 smaller cohorts of students taught by multiple faculty (including the nurse epidemiologist (author)), at multiple campuses, using identical curriculum.
\end{abstract}

Results: A moderate, but significant difference in student achievement was noted between the courses taught by the nurse epidemiologist as compared to the other cohorts.

Conclusions: Critical faculty shortages and the need for updated public health nursing education call for innovative teaching approaches. A commonly developed epidemiology course can be delivered at multiple campuses by generic faculty with minor loss of student achievement.

\section{Key words}

Nursing education, Program evaluation, Public health nursing education, Epidemiology, Population-based nursing

\section{I ntroduction}

One western U.S. university with a history of distance delivery recently revised its entire undergraduate nursing curriculum. Derived from three Institute of Medicine reports (IOM, 2003) ${ }^{[1-3]}$, the new curriculum incorporated, among other aspects, (1) a specialized epidemiology course as a core curricular element, and (2) expansion of distance learning options to improve access to nursing education. Few nursing faculty, however, were fully prepared in epidemiology to develop and deliver the new course at distant campus sites. A common curriculum was developed by a nurse 
epidemiologist (author), and taught by nursing faculty variously prepared in public health nursing. This study builds on two previous evaluations of public health course content ${ }^{[4,5]}$, and aims to answer the question "can an expert-designed epidemiology course be delivered at multiple sites by generic faculty with no loss of student achievement?”

\section{Background}

The Institute of Medicine's report "Who Will Keep the Public Healthy” (2003), requires the reform of public health education and improved preparation of the public health workforce ${ }^{[1]}$. Specifically, the report "emphasize[s] the importance and centrality of the ecological approach" (p. 5). In particular, the report recommends that "undergraduate schools [of nursing] be encouraged to assure that curricula are designed to develop an understanding of the ecological model of health and core competencies in population-focused practice” (p. 19). In support of a broader working knowledge of public health science, Macdonald (2004) ${ }^{[6]}$ also called for nursing education to be updated in epidemiology, the science of public health, pointing out that most textbooks refer to theory popular as much as a generation ago. The IOM report also advocated for distance learning as a means to broaden access to public health education ${ }^{[1] .}$

A previous study evaluated distance learning, student satisfaction, and relevance to practice of two courses designed to support learning goals and outcomes specific to the ecological model and population health, which are public health concepts related to newer theories of epidemiology ${ }^{[4]}$. In addition, the previous study set out to address larger goals elaborated by the Quad Council for public health nursing practice ${ }^{[7]}$, as well as IOM goals for practical application of the ecologic approaches and availability of distance learning ${ }^{[1]}$. The study found that an extremely well integrated effort, a large number of collaborative faculty, and extensive technological support and expertise were required ${ }^{[4]}$.

Although highly resource intensive, students evaluated the two courses very positively in terms of application to practice and their understanding of population health concepts, including structural determinants of health and the ecological approach. Faculty were greatly challenged to perform in and coordinate several different settings, but were enthusiastic about student learning. Based on outcomes from their class experience, faculty agreed to incorporate several elements in future iterations of classes, including the on-line platform to integrate clinical and theory components, particular media illustrating the ecological approach, and student evaluation rubrics for class discussion. Subsequent to the delivery of these two courses, faculty not involved in teaching adopted a number of the integrated technology elements into their classes. In addition, community concepts were introduced into a lower level course to establish an early understanding of population health determinants ${ }^{[4]}$.

While the previous study was deemed a success on several levels, the courses were largely developed and taught by several faculty with no or limited preparation in epidemiology, failing therefore to consistently meet Macdonald's call for an "updated synthesis of public health science and nursing science" ${ }^{[6]}$. Given the success of the previous study, combined with an extreme shortage of faculty qualified to teach epidemiology, the epidemiology course was redeveloped with a common curriculum for statewide in-class/on-line delivery at 5 campuses in the spring of 2010. It is this course that is evaluated here.

Although this study was designed to evaluate student outcomes from a common epidemiology curriculum, an implicit assumption is that both traditional and online delivery methods achieve similar learning outcomes ${ }^{[8]}$. The no significant difference effect suggests that course designers and teachers might choose the most convenient method to deliver instruction since there appears to be no significant difference between technology-enhanced and traditional instruction. Cost benefits are often cited as a primary motivator for choosing instructional technology delivery over traditional methods and the benefits of flexibility and accessibility to off-campus students via the Internet are also cited ${ }^{[9]}$. Indeed, in its report Evaluation of Evidence-based Practices in Online Learning: A Meta-Analysis and Review of Online Learning Studies, the US Department of Education screened over one thousand empirical studies of online learning in higher education and found that students in online learning conditions may perform better than those receiving traditional face-to-face instruction ${ }^{[10]}$. 
Other factors may affect learner outcomes in an online environment, however, and these involve social and educational components associated with the community of inquiry. Originally coined by the $19^{\text {th }}$ century philosopher Charles Sanders Peirce in reference to a community of scientists, Matthew Lipman, a US professor and philosopher, broadened the concept to education in general ${ }^{[11]}$. Further expanded to include computer-mediated communication, three elements are essential in the educational process: cognitive presence, social presence, and teaching presence. Cognitive presence ensures that learners are able to construct meaning through sustained communication with faculty. Social presence enables learners to see themselves as a part of a community of scholars. Teaching presence establishes the direction and content of the learning process in the learner's mind ${ }^{[12]}$. It is this collection of variables known as the community of inquiry that may go missing when students do not have ready access to a content expert (a nurse epidemiologist in the present case).

\section{Purpose of this study}

The purpose of this study was to understand whether an innovative, multi-campus, multi-faculty on-line course could be delivered at several campus sites without sacrificing the student experience. This study was designed to answer the question: can an expert-designed common epidemiology course be delivered at multiple sites by generic faculty with no loss of student achievement?

\section{Methods}

\subsection{Study design}

Final exam score averages were compared between 5 campuses and 6 nursing student cohorts, using identical course content and the same exam. Four campus cohorts were taught using "generic" nursing faculty, the 5th was taught by the nurse epidemiologist who designed the course. The 6th cohort—developed and taught by the nurse epidemiologist-was the combined cohorts taught using the same content prior to implementation of the multi-faculty, multi-campus cohorts and used as a baseline comparison.

\subsection{Sample}

The sample consisted of 329 baccalaureate nursing students enrolled in required epidemiology courses between 2009 and 2011. One hundred thirty eight (138) of the total student sample was enrolled in four courses over the three year period with a single faculty instructor with advanced preparation in epidemiology (author) (the 6th cohort or Campus “F” below). The students enrolled in these four courses were admitted to a single campus, and consisted of traditional undergraduate and accelerated baccalaureate nursing students. Each course was delivered in a hybrid format with three face-to-face synchronous sessions at the campus, and the remaining content delivered via the Sakai on-line learning platform.

The remaining 191 students were taught in a single common course, divided into sections, using an identical curriculum, and taught by several different faculty members at 5 campuses of the same university. Each section was delivered in a hybrid format with three face-to-face synchronous sessions at one of the campus locations and the remaining content delivered via the Sakai on-line learning platform, identical to the 6th comparison cohort course format (campus "F" below), except that the three face-to-face sessions were developed and delivered by faculty of record on each campus. Facilitation of the on-line portion of the course was done by 6 faculty of record, plus 4 additional instructors, with students divided into groups of 8-10 discussion sections.

\subsection{Data collection}

Data were collected using the on-line platform. A 25 question, multiple-choice, time-limited, random question assignment exam was given at the end of each term. Answers were tallied and grades calculated automatically in Sakai. Final exam scores were analyzed. 


\subsection{Statistical analysis}

Final exam score averages were compared among and between all cohorts, before and after implementation of the common course. A one-way between subjects ANOVA was conducted to compare the effect of the cohort on the final test score averages. Homogenous variances were not assumed because of the variable sample size for each cohort. A post-hoc test was conducted using the Dunnett's $C$ test, which does not assume equality of variances. Since the research was conducting multiple tests of significance, the level of significance was conservatively adjusted $(p<.017)$.

\section{Results}

Some differences were noted in comparing the cohorts. Cohorts A-D were taught by generic faculty at one of 5 campuses. Cohort $\mathrm{E}$ is the student group for whom the course was delivered by the nurse epidemiologist (author). Cohort $\mathrm{F}$ is the combined sections of the prior course, developed and taught by the nurse epidemiologist, and used for comparison purposes to the common curriculum cohorts. To test for possible differences in performance between the cohorts, final test score averages were used as the dependent variable. The descriptive statistics in Table 1 illustrate that students in cohort F, the comparison cohort classes delivered by the nurse epidemiologist, tended to perform slightly better overall.

Table 1. Descriptive Statistics for Final Exam Score Averages

\begin{tabular}{llll}
\hline Cohort* & Mean & Std. Deviation & N \\
\hline A & 87.5 & 6.07 & 52 \\
B & 88.3 & 4.08 & 25 \\
C & 86.4 & 7.73 & 27 \\
D & 89.4 & 4.03 & 26 \\
E & 91.5 & 5.01 & 61 \\
F & 91.8 & 4.44 & 138 \\
Total & 90.2 & 5.46 & 329 \\
\hline
\end{tabular}

*Cohorts A-D represent students taught by "generic" faculty. Cohort E represents students taught concurrently by the nurse epidemiologist. Cohort $\mathrm{F}$ is the combined student groups taught by the nurse epidemiologist prior to implementation of the multi-campus, multi-faculty course.

\section{Data analysis}

To test the assumption that cohort F students performed slightly better than the other cohorts, a one-way between subjects ANOVA was conducted to compare the effect of the cohort on the final test score averages. The ANOVA was significant $F(5,323)=10.14, p=.000$. The relationship assessed by $n^{2}$, was moderate, with the cohort factor accounting for $14 \%$ of the variance of the dependent variable. This means that factors associated with the cohorts themselves do have some impact on the performance of students.

Follow-up tests were conducted to evaluate pairwise differences between the means of each cohort. Because of variation in sample size, homogenous variances were not assumed and a post-hoc test was conducted using the Dunnett's C test, which does not assume equality of variances. Since the research was conducting multiple tests of significance, the level of significance was conservatively adjusted $(p<.017)$. The results of this analysis are presented in Table 2, revealing few differences between cohorts taught by generic faculty, and a significant, though small difference between the cohorts taught by the nurse epidemiologist (cohort $\mathrm{E}$ ), the prior cohort comparison $\mathrm{F}$ and the cohorts taught by generic faculty (A-D). 
Table 2. Multiple Comparison of Final Exam Score Averages With Dunnett's C Correction

\begin{tabular}{|c|c|c|c|c|c|}
\hline \multirow{2}{*}{ (I) Cohort } & \multirow{2}{*}{ (J) Cohort } & \multirow{2}{*}{ Mean Difference (I-J) } & \multirow{2}{*}{ Std. Error } & \multicolumn{2}{|c|}{ 98.3\% Confidence Interval } \\
\hline & & & & Lower Bound & Upper Bound \\
\hline \multirow{5}{*}{ A } & $\mathrm{B}$ & -.83 & 1.17 & -4.90 & 3.23 \\
\hline & $\mathrm{C}$ & 1.14 & 1.71 & -4.85 & 7.13 \\
\hline & $\mathrm{D}$ & -1.84 & 1.16 & -5.84 & 2.15 \\
\hline & $\mathrm{E}$ & $-3.97^{*}$ & 1.06 & -7.53 & -.41 \\
\hline & $\mathrm{F}$ & $-4.28^{*}$ & .92 & -7.38 & -1.19 \\
\hline \multirow{5}{*}{ B } & A & .83 & 1.17 & -3.23 & 4.90 \\
\hline & $\mathrm{C}$ & 1.97 & 1.70 & -4.05 & 7.99 \\
\hline & $\mathrm{D}$ & -1.02 & 1.14 & -5.06 & 3.04 \\
\hline & $\mathrm{E}$ & -3.14 & 1.04 & -6.76 & .48 \\
\hline & $\mathrm{F}$ & $-3.45^{*}$ & .90 & -6.61 & -.29 \\
\hline \multirow{5}{*}{$\mathrm{C}$} & A & -1.14 & 1.71 & -7.13 & 4.90 \\
\hline & $\mathrm{B}$ & -1.97 & 1.70 & -7.99 & 4.06 \\
\hline & $\mathrm{D}$ & -2.98 & 1.69 & -8.96 & 2.99 \\
\hline & $\mathrm{E}$ & -5.11 & 1.62 & -10.81 & .58 \\
\hline & $\mathrm{F}$ & $-5.42^{*}$ & 1.54 & -10.84 & -.01 \\
\hline \multirow{5}{*}{ D } & A & 1.85 & 1.16 & -2.15 & 5.84 \\
\hline & B & 1.02 & 1.14 & -3.04 & 5.07 \\
\hline & C & 2.99 & 1.69 & -2.99 & 8.96 \\
\hline & $\mathrm{E}$ & -2.13 & 1.02 & -5.67 & 1.41 \\
\hline & $\mathrm{F}$ & -2.44 & .88 & -5.51 & .64 \\
\hline \multirow{5}{*}{$\mathrm{E}$} & A & $3.97^{*}$ & 1.06 & .42 & 7.53 \\
\hline & B & 3.14 & 1.04 & -.48 & 6.76 \\
\hline & C & 5.11 & 1.62 & -.58 & 10.81 \\
\hline & $\mathrm{D}$ & 2.13 & 1.02 & -1.41 & 5.67 \\
\hline & $\mathrm{F}$ & -.31 & .75 & -2.79 & 2.17 \\
\hline \multirow{5}{*}{$\mathrm{F}$} & A & $4.28^{*}$ & .92 & 1.19 & 7.38 \\
\hline & B & $3.45^{*}$ & .90 & .29 & 6.61 \\
\hline & C & $5.42^{*}$ & 1.54 & .01 & 10.84 \\
\hline & $\mathrm{D}$ & 2.44 & .88 & -.64 & 5.51 \\
\hline & $\mathrm{E}$ & .31 & .75 & -2.17 & 2.79 \\
\hline
\end{tabular}

$* p<.017$

\section{Discussion}

The literature reveals that a hybrid course offering likely has no adverse effect on student learning and may even show modest gains in measures of mastery when compared to face-to-face learners ${ }^{[8]}$. The no significant difference effect premise supports the use of technology in education when it is cheaper and/or more convenient than traditional methods. This is of particular importance in nursing education to stretch limited faculty expertise to meet nursing education needs. Course design, structure, and faculty expertise, however, can have significant impacts on the nature of interaction and whether students approach learning in a deep and meaningful way. For the present study, Garrison's design variable ${ }^{[13]}$ as well as course structure were held constant because all versions of the course were designed by the authors. Teacher presence may have varied as the comparison cohort (A-D) were taught at different locations and discussion facilitated by different faculty.

Social and cognitive presence in the comparison cohort course (F) were positively evaluated in previous analyses of course content and delivery ${ }^{[5]}$. Faculty facilitation (teacher presence) of online learning may also affect student performance especially when self-reflection is tapped. In the current study, the cohort variable may represent faculty variation, accounting the differences in achievement between cohorts. The instructor who developed the course, by virtue of being a 
content expert, may have been particularly adept at activating learning among students, as well as facilitating and encouraging self-reflection over the course content thereby enhancing social and cognitive presence in those cohorts.

Conversely, the generic faculty expressed the belief that their students were generally less sophisticated than the cohort taught by the nurse epidemiologist, possibly explaining differences in student performance between campuses. During the course of this study, however, it was discovered that at least $30 \%$ of students admitted to campuses other than the main university campus were residents of the main campus area, undermining to some extent differences in student sophistication as an explanatory variable. In addition, the comparison cohort courses (F) had been employed in diverse student populations (traditional undergraduate and accelerated baccalaureate) with no significant differences in learning outcomes ${ }^{[4]}$. The effect size in comparing learning outcomes between the courses was moderate, although not negligible at $14 \%$. Similarly, while the differences in achievement were significant between cohorts, they were also moderate ( $86 \%$ $92 \%$ range of final exam score averages).

\section{Conclusions}

In summary, it appears that a common curriculum developed by a content expert combined with distance learning strategies can be used to good advantage to meet the need for nursing education and stretch nursing faculty capacity. The community of inquiry, specifically social, cognitive and teaching presence, and therefore learning outcomes may, however, be affected to some extent by the use of faculty not specifically prepared in the course subject matter. Given these findings, implications for future study might include exploration of the role of advanced training, continuing education, and faculty development for nursing faculty teaching common curriculum courses. Overall, students performed well in this innovative, multi-campus, multi-instructor, common curriculum, distance-delivered course supporting the hypothesis that a common curriculum can be successfully employed to teach epidemiology, and in support of goals to update public health nursing curriculum ${ }^{[6]}$.

\section{Study limitations}

Characteristics of the faculty and/or the students may explain some variation in cohort achievement. The nurse epidemiologist developed and taught the epidemiology course for several prior cohorts. The "generic" faculty had taught versions of their own design in the past, and participated in the design of the multi-campus, multi-faculty course to some extent. Nevertheless, differences in cohort performance on final exam may reflect deficiencies in teaching or cognitive presence based on unfamiliarity with the course rather than lack of expertise in the subject matter. Also, faculty, in preparation for the course, expressed the belief that students at the urban campus ( $\mathrm{E}$ and $\mathrm{F}$ cohorts) were more sophisticated and amenable to complex topics, which could explain performance differences. After registration, however, it was determined that a significant minority of students were urban residents registered at rural campuses, undermining that hypothesis to some extent.

\section{References}

[1] Institute of Medicine. Who will keep the public healthy? Educating health professionals for the 21st century. Washington DC: National Academy Press. 2003a.

[2] Institute of Medicine. The Future of the Public's Health in the 21st Century. Washington, DC, National Academy Press. 2003b.

[3] Institute of Medicine. Health Professions Education: A bridge to quality. Washington DC: National Academy Press. 2003c.

[4] Sistrom M, Zeigen L, Durham K, Jones M, Boudrot T. Integrated Methods for Teaching Public Health. Journal of Nursing Education. 2001; 50(1): 35-39. PMid:21053860 http://dx.doi.org/10.3928/01484834-20101029-02

[5] Sistrom M, Hale P. 2008. Teaching Epidemiology: The Role of the Public Health Nurse. Journal of Nursing Education. 2008; 47(5): 227-230. PMid:18522155 http://dx.doi.org/10.3928/01484834-20080501-07

[6] Macdonald M. From Miasma to Fractals: The epidemiologic revolution and public health nursing. Public Health Nursing. 2004; 21(4): 380-91. PMid:15260844 http://dx.doi.org/10.1111/j.0737-1209.2004.21412.x 
[7] The Quad Council of the Public Health Nursing Section of the American Public Health Association, Association of Community Health Nurse Educators, Association of State and Territorial Directors of Nursing, and the American Nurses Association. Available from: http://www.apha.org/membergroups/sections/aphasections/phn/Resources/phnquad.htm (25 June 2013, date last accessed

[8] Russell TL. The no significant difference phenomenon. Raleigh, N.C.: North Carolina State University. 1999.

[9] Campbell M, Gibson W, Hall A, Richards D, Callery P. Online vs. face-to-face discussion in a web-based research methods course for postgraduate nursing students: A quasi-experimental study. International Journal of Nursing Studies. 2008; 45(5): 750-759. PMid:17306272 http://dx.doi.org/10.1016/j.ijnurstu.2006.12.011

[10] Means V, Toyama Y, Murphy R, Bakia M, Jones K. Evaluation of evidence-based practices in online learning: A meta-analysis and review of online learning studies. U.S. Department of Education. 2010.

[11] Lipman, M. Thinking in Education. New York, NY Cambridge University Press. 1994.

[12] Garrison DR, Anderson T, Walter A. Critical inquiry in a text-based environment: Computer conferencing in higher education. The Internet and Higher Education. 2000; 2(2-3): 87-105. http://dx.doi.org/10.1016/S1096-7516(00)00016-6

[13] Garrison DR, Cleveland-Innes M. Facilitating cognitive presence in online learning: Interaction is not enough. The American Journal of Distance Education. 2005; 19(3): 133-148. http://dx.doi.org/10.1207/s15389286ajde1903_2 